\title{
Comparison of Serum Malondialdehyde Levels in Vitiligo Patients and Healthy Controls
}

\author{
Mary Vineetha ${ }^{1}$, Seena Palakkal ${ }^{2}$ \\ ${ }^{1}$ Department of Dermatology, Government Medical College, Kottayam, Kerala, India. \\ ${ }^{2}$ Department of Dermatology, Government Medical College, Kottayam, Kerala, India.
}

\section{ABSTRACT}

\section{BACKGROUND}

Vitiligo is an idiopathic, acquired, circumscribed, hypomelanotic skin disorder, characterized by depigmented or hypopigmented macules of different sizes and shapes. It is due to the destruction of melanocytes resulting in the absence of pigment production of the skin and mucosal surfaces. Oxidative stress has been implicated in pathophysiology of vitiligo. Oxidative stress reflects an imbalance between the production of reactive oxygen species and biological system's ability to readily detoxify the reactive intermediates or to repair the resulting damage. ${ }^{1}$ Malondialdehyde (MDA) is one of several low-molecular-weight end products formed via the decomposition of certain primary and secondary lipid peroxidation products. It is one of the important indicators of free radical-mediated tissue injury.

\section{METHODS}

In this case control study, the serum MDA levels of 50 vitiligo patients were compared with 50 age and sex matched controls. Analysis was done in UV - Vis spectrophotometer and Malondialdehyde (MDA) was measured in the serum by a method based on Valipasha and Sadasivadu's procedures for estimation of MDA.

\section{RESULTS}

MDA levels were high in cases and in patients with unstable and generalized vitiligo than in control group and stable and localized vitiligo with a significant $\mathrm{p}$ value. There was no significant gender difference in oxidative stress. This study concludes that oxidative stress has a significant role in development of vitiligo.

\section{CONCLUSIONS}

There is oxidative stress in vitiligo as the serum level of malondialdehyde a marker of lipid peroxidation is elevated in vitiligo cases compared to controls.

\section{KEY WORDS}

Vitiligo, Oxidative Stress, Malondialdehyde (MDA), Thiobarbituric Acid (TBA)
Corresponding Author:

Dr. Seena Palakkal,

Associate Professor,

Department of Dermatology, Government Medical College, Kottayam, Kerala, India.

E-mail: drmaryvineetha@gmail.com

DOI: $10.14260 /$ jemds/2020/78

Financial or Other Competing Interests: None.

How to Cite This Article:

Vineetha M, Palakkal S. Comparison of serum malondialdehyde levels in vitiligo patients and healthy controls. J. Evolution Med. Dent. Sci. 2020;9(06):343-346, DOI: $10.14260 / \mathrm{jemds} / 2020 / 78$

Submission 04-11-2019,

Peer Review 18-01-2020,

Acceptance 24-01-2020,

Published 10-02-2020. 


\section{BACKGROUND}

Vitiligo is an idiopathic, acquired, circumscribed, hypomelanotic skin disorder, characterized by depigmented or hypopigmented macules of different sizes and shapes. It is due to the destruction of melanocytes resulting in the absence of pigment production of the skin and mucosal surfaces. The precise aetiology of vitiligo is not known. Various hypotheses include biochemical hypothesis ${ }^{2}$, neural hypothesis, autoimmune hypothesis, defective free radical defence $^{3}$ deficiency of melanocyte growth factors, intrinsic defect of melanocyte adhesion and genetic predisposition. The biochemical theory involves two main components, elevated catecholamine and altered antioxidant defense. ${ }^{4}$ Oxidative stress is reported to play a role in progression of vitiligo but there is conflicting evidence for the same. Some researchers report increased total antioxidant levels, others report no change or even decreased levels of these markers like Superoxide Dismutase (SOD), Glutathione peroxidase (GPx), Malondialdehyde (MDA), Nitric Oxide (NO), and Catalase. ${ }^{5}$ Oxidative stress is an expression used to describe various deleterious process resulting from an imbalance between excessive formation of ROS and limited antioxidant defences. Prime targets of peroxidation by ROS are poly unsaturated fatty acid (PUFA) in membrane lipids. Decomposition of peroxidised lipids yields a variety of end products which include malondialdehyde (MDA). It is well known that MDA serves as a reliable marker of free radicalmediated lipid peroxidation. ${ }^{6}$ Thiobarbituric acid reactive substances - TBARS - are formed as a by-product of lipid peroxidation. MDA reacts with Thiobarbituric acid (TBA) to generate a coloured product which can be measured spectrophotometrically. ${ }^{7}$ TBA test detects only free MDA and measures the amount of free MDA in peroxidising lipid system. So, this study was conducted to compare the serum levels of MDA in vitiligo cases and normal controls and to find if there is oxidative stress in vitiligo.

\section{METHODS}

The study was conducted in Dept., of Dermatology Medical College Calicut with the help of Dept., of Biochemistry Govt. medical college Calicut for one year after getting permission from Institutional Review Board. Informed consent was obtained from both patients and controls for enrolling in study. It was a prospective case control study and the sample size was 50 according to formula $4 \mathrm{pq} / \mathrm{d}^{2}$ ( $\mathrm{p}$ is the prevalence, $\mathrm{q}$ is $100-\mathrm{p}, \mathrm{d}$ is precision of reference study). Clinically diagnosed cases of vitiligo in the age group of 20- 40 yrs., were included in this study. It was an unmatched case control study and control include healthy volunteers.

Chronic smokers, alcoholics, patients with history of diabetes mellitus, hypertension, renal disease, malignancies, neurological disease, patients on systemic drugs, pregnant females were not included in this study. A thorough history regarding site of onset, duration of disease, stability of disease, family history, treatment taken were recorded. General, physical examination and dermatological examination done. Stability of vitiligo was defined according to IADVL task force recommendation that is no new lesions and absence of extension of existing lesions for one year.

Blood samples, $3 \mathrm{ml}$ was collected by venous puncture using disposable syringes and needles under sterile precaution and transferred into clean dry containers. Blood was allowed to clot, and the serum separated by centrifugation at 3,000 rpm for five minutes. Analysis was done in UV - Vis spectrophotometer. Malondialdehyde (MDA) was measured in the serum by the method based on Valipasha and Sadasivadu's procedures for estimation of MDA. ${ }^{8}$ MDA reacts with Thiobarbituric acid (TBA) to generate a coloured product which can be measured spectrophotometrically. In acidic solution, the product absorbs light at $530 \mathrm{~nm}$. TBA test detects only free MDA and measures the amount of free MDA in peroxidising lipid system. The molar extinction coefficient of MDA - TBA product is $\left(1.54 \times 10^{5}\right)$ at $530 \mathrm{~nm}$ and it is used to calculate the amount of MDA formed.

\section{Reagents}

1. $40 \%$ Trichloro acetic acid (TCA)

2. $0.67 \%$ Thiobarbituric acid (TBA)

\section{Procedure}

$1 \mathrm{ml}$ of serum added to $1 \mathrm{ml}$ of $40 \%$ TCA followed by addition of $2 \mathrm{ml}$ of $0.67 \%$ TBA. The mixture was then kept for 10 minutes in a boiling water bath. It was cooled immediately in ice cold water bath. The mixture was then centrifuged at $6000 \mathrm{rpm}$ for 30 seconds and absorbance of supernatant was read at $530 \mathrm{~nm}$.

\section{Calculation}

$\mathrm{E}=\mathrm{kCL}$

$\mathrm{C}=\mathrm{E} / \mathrm{Kx} \mathrm{L}=\ldots \ldots \ldots \ldots \ldots . . . \mathrm{nmol} / \mathrm{dl}$.

$\mathrm{K}=$ Molar extinction co-efficient (Extinction offered by 1 molar solution) i.e., $1.5 \times 10^{5}$

$\mathrm{E}=$ Extinction/Absorbance.

$\mathrm{C}=$ Concentration in moles/ litre.

$\mathrm{L}=$ Length of cuvette used $(1 \mathrm{~cm})$.

Normal Range: 70-110 nmol/ $100 \mathrm{ml}$ (Valipasha \& Sadasivadu).

Statistical analysis was done using SPSS software and chi square test, Independent $t$ test and unpaired $t$ test were done to analyse data.

\section{RESULTS}

In this study 50 cases of vitiligo patients who attended the outpatient department and who satisfied the inclusion criteria were studied. Their serum Malondialdehyde (MDA) levels were compared with that of normal controls. Out of 50 patients 22 were males. Male female ratio was 1.27:1. 30 cases were generalized and 20 were localized vitiligo out of which 20 and 15 were unstable respectively. Vitiligo vulgaris was the most common type followed by focal vitiligo, acrofacial vitiligo, mucosal and 2 cases each of segmental vitiligo and vitiligo universalis. All cases of vitiligo vulgaris, focal vitiligo and vitiligo universalis were unstable and all cases of segmental vitiligo, mucosal vitiligo and acrofacial 
vitiligo were stable. Leukotrichia was seen in $20 \%$. Association of vitiligo with thyroid disease was $2 \%$. No case of diabetes was found on screening. Family history of vitiligo was $4 \%$. Extremity was the site of onset in $76 \%$.

Unstable vitiligo was more common in age group 30-40 yrs, with a significant $p$ value of 0.01 on chi- square testing. Mucus membrane involvement was found to be least in unstable vitiligo with a significant $\mathrm{p}$ value of 0.001 on chi square testing. Mucus membrane involvement was more common in generalized vitiligo than localized with a significant $\mathrm{p}$ value of 0.001 . Palm and sole involvement was more common in generalized vitiligo with a significant chisquare of 0.001 . The site of onset was most common in extremities with a $\mathrm{p}$ value of 0.01 from chi square testing. Independent $t$ test was done to compare cases and controls. MDA levels in generalized vitiligo was more than localized vitiligo with a $\mathrm{p}$ - value of 0.001 on unpaired t- testing (Table1). MDA level in unstable vitiligo was compared with stable vitiligo and was found to be significantly elevated with a pvalue of 0.001 (Table-1). MDA levels in cases were significantly higher than control with a p-value of 0.001 on $t$ testing. MDA level was normal in segmental vitiligo with a mean value of $89.6 \mathrm{nmol} / 100 \mathrm{ml}$ and was maximum in vitiligo universalis $221 \mathrm{nmol} / 100 \mathrm{ml}$. (Fig. 1)

MDA levels were compared between male and females in cases and controls which showed no significance on unpaired t testing (Table-2). On comparing the age group and MDA levels in cases and controls significantly higher levels were found in age group 30 to 40 in cases, with a p-value of 0.001 . (Table 3).

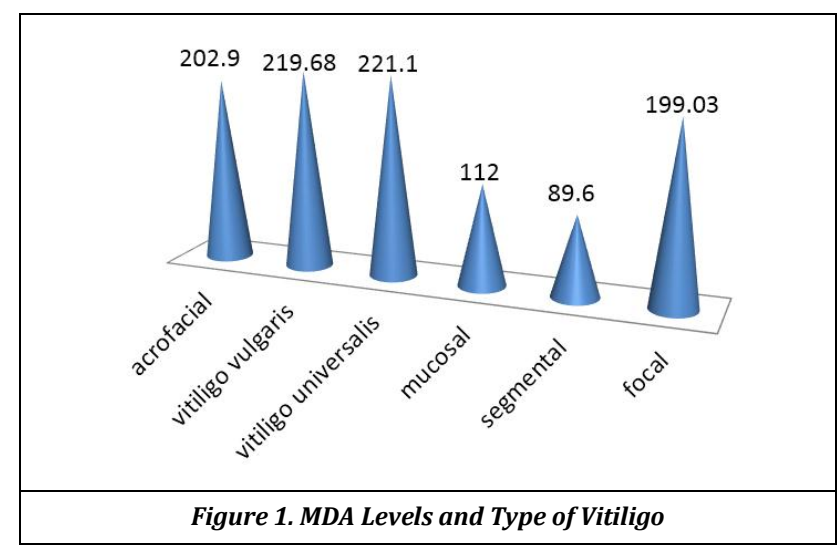

\begin{tabular}{|c|c|c|c|c|c|}
\hline \multirow{2}{*}{ Type } & Generalized & $\begin{array}{c}\text { Mean } \\
\text { MDA }\end{array}$ & $\begin{array}{c}\text { Std } \\
\text { Deviation }\end{array}$ & $\begin{array}{c}\text { t- Test } \\
\text { Value }\end{array}$ & p Value \\
\cline { 2 - 5 } & Localized & 167.3 & 9.67 & & \\
\multirow{2}{*}{ Stability } & Stable & 168.3 & 45.3 & 5.23 & 0.001 \\
\cline { 2 - 4 } & Unstable & 205.2 & 22.8 & 3.68 & 0.001 \\
\hline \multicolumn{7}{|c|}{ Table 1. Comparison of MDA Levels (nmol/100 ml) with type of } \\
Vitiligo and Stability \\
\hline
\end{tabular}

\begin{tabular}{|c|c|c|c|c|c|}
\hline & & $\begin{array}{c}\text { Mean MDA } \\
\text { cases }\end{array}$ & S.D. & $\begin{array}{l}\text { t-test } \\
\text { Value }\end{array}$ & p Value \\
\hline \multirow{2}{*}{ Gender } & Male & \begin{tabular}{|l|l|}
204.2 \\
\end{tabular} & 11.2 & \multirow[b]{2}{*}{1.7} & \multirow[b]{2}{*}{0.07} \\
\hline & Female & 186 & 46.6 & & \\
\hline \multicolumn{6}{|c|}{ Table 2. Comparison of MDA Levels with Gender } \\
\hline
\end{tabular}

\begin{tabular}{|c|c|c|c|c|c|}
\hline & Age Group & Mean MDA & Std Deviation & t Test & p Value \\
\hline \multirow{2}{*}{ Cases } & 20-30 Years & 171.8 & \begin{tabular}{|l|}
50.9 \\
\end{tabular} & \multirow[b]{2}{*}{3.7} & \multirow[b]{2}{*}{0.001} \\
\hline & $30-40$ Years & 207.6 & 11.13 & & \\
\hline \multirow{2}{*}{ Controls } & 20-30 Years & 89.3 & 15.1 & \multirow[b]{2}{*}{0.93} & \multirow[b]{2}{*}{0.35} \\
\hline & $30-40$ Years & 84.9 & 14.8 & & \\
\hline \multicolumn{6}{|c|}{ Table 3. Comparison of MDA (nmol/100ml) with Age Group } \\
\hline
\end{tabular}

\section{DISCUSSION}

The precise aetiology of vitiligo is unknown. Imbalance in redox homeostasis due to elevated levels of $\mathrm{H}_{2} \mathrm{O}_{2}$ may induce the Fenton type hydroxylation process converting tyrosine or exogenous monophenols to catechols. ${ }^{9}$ A slight female preponderance was seen in our study and this is in concordance with study conducted by Shajil ${ }^{10}$ and Daneshpazhooh ${ }^{11}$ who also noted female preponderance. Most of the reports showed that males and females were affected with almost equal frequency, but females outnumbered males in our study presumably because social stigma and marital concerns prompt women to seek early consultation. Vitiligo vulgaris was found to be the most common clinical type of vitiligo as has also been reported by Beazley et al. ${ }^{12}$ and Shajil et al. ${ }^{10}$ The frequency of distribution of clinical types of vitiligo varies in different studies. However, according to the reports of Koranne et al. ${ }^{13}$ and Sarin et al.,14 generalized vitiligo was found to be more common. Thus, our results suggest that Indians not only have an increased incidence of the disease but also have more widespread disease. Leukotrichia was seen in $20 \%$ but this was seen in $9 \%$ in a study by Hita shah. ${ }^{15}$ The association of vitiligo with thyroid disease was $2 \%$ in our study but was reported to be $12 \%$ by Gopal et al ${ }^{16}$ and $0.27 \%$ by Hita Shah et $\mathrm{al}^{15}$. Insulin-dependent diabetes mellitus is found in $1 \%$ to $7 \%$ of patients with vitiligo, [in various studies but was nil in our study. Familial occurrence has been reported to be in the range of $6.25 \%$ to $30 \% .{ }^{17}$ Positive family history is considered to be a poor prognostic factor for vitiligo. In our study it was $4 \%$. In Hita Shah et al study it was $13.7 \% .{ }^{15}$

Site of onset was extremities in majority of patients, and this was in concordance with study by Rita V Vora et al. ${ }^{18}$ MDA levels in cases were significantly higher than control with a p-value of 0.001 on $t$ testing(Table-9). This was in concordance with studies conducted by Khan R, Arican $\mathrm{O}$ and Koca R. ${ }^{19,20,21}$ Sravani PV and Babu NK has demonstrated oxidative stress in skin of vitiligo patients. ${ }^{22}$ MDA level was normal in segmental vitiligo with a mean value of 89.6 $\mathrm{nmol} / 100 \mathrm{ml}$ and was maximum in vitiligo universalis 221 $\mathrm{nmol} / 100 \mathrm{ml}$. Singh D et al also noted elevated levels of MDA in progressive disease and those with large surface area involvement. ${ }^{23}$ There was no sex difference in the MDA levels and the levels of MDA in cases was highest in $2^{\text {nd }}$ decade and this finding was statistically significant.

\section{CONCLUSIONS}

There is oxidative stress in vitiligo as the serum level of malondialdehyde a marker of lipid peroxidation is elevated in vitiligo cases compared to controls. This oxidative stress is more in generalized and progressive disease. Oxidative stress has a role in the development and progression of vitiligo.

\section{REFERENCES}

[1] Vasudevan DM, Sreekumari S. Free radicals and antioxidants. Text book of Biochemistry (For Medical 
Students). $3^{\text {rd }}$ edn. New Delhi: Jaypee Brothers Medical Publishers 2001: p. 212-5.

[2] Boissy RE, Manga P. On the etiology of contact/occupational vitiligo. Pigment cell Res 2004;17 (3):208-14.

[3] Schallreuter KU. Oxidative stress in human epidermis. G Ital Dermatol Venereol 2005;140:505-14.

[4] Napolitano A, Crescenzi O, Pezzella A, et al. Generation of the neurotoxin 6 hydroxydopamine by peroxidase/h202 oxidation of dopamine. J Med Chem 1995;38 (6):917-22.

[5] Jain A, Mal J, Mehndiratta V, et al. Study of oxidative stress in vitiligo. Indian J Clin Biochem 2011;26 (1):7881.

[6] Nielsen F, Mikkelsen BB, Nielsen JB, et al. Plasma malondialdehyde as biomarker for oxidative stress: reference interval and effects of life-style factors. Clin Chem 1997;43 (7):1209-14.

[7] Ozturk IC, Batcioglu K, Karatas F, et al. Comparison of plasma malondialdehyde, glutathione, glutathione peroxidase, hydroxyproline and selenium levels in patients with vitiligo and healthy controls. Indian Journal of Dermatology 2008;53 (3):106-10.

[8] Pasha KV, Sadasivadu B. Intracellular content of thiol compounds, thiobarbituric acid reactive substances and gamma-glutamyl transpeptidase in rat brain during anoxia. Neurosci Lett 1984;46 (2):209-14.

[9] Han R, Baden HP, Brissette JL, et al. Redefining the skin's pigmentary system with a novel tyrosinase assay. Pigment Cell Res 2002;15 (4):290-7.

[10] Nischal HK, Sharma MP, Goyal RK, et al. Serum superoxide dismutase levels in diabetes mellitus with or without microangiopathic complications. JAPI 1998; 46:853-5.

[11] Ghalaut VS, Ghalaut PS, Singh S. Lipid peroxidation in leukemia. JAPI 1999;47 (4):403-5.

[12] Briganti S, Picardo M. Antioxidant activity, lipid peroxidation and skin diseases. What's new? J Eur Acad Dermatol Venereol 2003;17 (6):663-9.
[13] Vijayaraghavan R, Suribabu CS, Sekar B, et al. Protective role of vitamin $\mathrm{E}$ on the oxidative stress in Hansen's disease (Leprosy) patients. Eur J Clin Nutr 2005;59 (10):1121-8.

[14] Rahimi R, Nikfar S, Larijani B, et al. A review on the role of antioxidants in the management of diabetes and its complications. Biomed Pharmacother 2005;59(7):36573.

[15] Shah H, Mehta A, Astik B. Clinical and sociodemographic study of vitiligo. Indian J Dermatol Venereol Leprol 2008;74 (6):701.

[16] Gopal KVT, Rao GRR, Kumar YHK, et al. Vitiligo: a part of a systemic autoimmune process. Indian J Dermatol Venereol Leprol 2007;73 (3):162-5.

[17] Locatelli F, Canaud B, Eckardt KU, et al. Oxidative stress in end-stage renal disease: an emerging threat to patient outcome. Nephrol Dial Transplant 2003;18 (7):1272-80.

[18] Vora RV, Patel BB, Chaudhary AH, et al. A clinical study of vitiligo in a rural set up of Gujarat. Indian J Community Med 2014;39 (3):143-6.

[19] Koca R, Armutu F, Altinyazar HC, et al. Oxidant antioxidant enzymes and lipid peroxidation in generalized vitiligo. Clin Exp Dermatol 2004;29 (4):4069.

[20] Arican 0, Kurutas EB. Oxidative stress in the blood of patients with active localized vitiligo. Acta Dermatol Venerol 2008;17 (1):12-6.

[21] Khan R, Satyam A, Gupta S, et al. Circulatory levels of antioxidants and lipid peroxidation in Indian patients with genralised and localized vitiligo. Arch Dermatol Res 2009;301 (10):731-7.

[22] Sravani PV, Babu NK, Gopal KVT, et al. Determination of oxidative stress in vitiligo by measuring SOD and catalase levels in Vitiliginous and non-vitiliginous skin. Indian J Dermatol Venerol Leprol 2009;75 (3):268-71.

[23] Singh D, Malhotra SK, Gujral U. Role of oxidative stress in autoimmune pathogenesis of vitiligo. Pigment Int 2016;3 (2):90-5. 